\title{
KORELASI KADAR GULA DARAH PUASA DAN KUALITAS TIDUR MAHASISWA USIA 20-25 TAHUN DI STIKES MAHARANI
}

\author{
Sesi Mei Irawati \\ Program Studi S1 Keperawatan, STIKes Maharani \\ Email: sesimeiira@gmail.com
}

\begin{abstract}
Individuals are required to meet basic human needs, one of which is sleep.Sleep disorders play an important role in the development of diabetes through the neuroendocrine metabolic pathway. People who suffer from sleep disorders, sleep quality or sleep quantity experience a decrease in insulin sensitivity and consequently an increase in blood glucose. This aims of this research was to identify the correlation between sleep quality and fasting blood sugar level in young adults. The design was correlational research with cross sectional approach. The sampling technique purposive sampling involving 38 respondents that was selected based on inclusion criteria. This research used question naire Pittsburgh Sleep Quality Index (PSQI) and blood glucose meter. The bivariate analysis use pearson test. The results of this study indicate that of the 38 respondents almost all respondents had poor sleep quality as many as 31 respondents (81.6\%) and most of the respondents included in the prediabetes category were 20 respondents (52.6\%). From the results of the Pearson correlation test obtained ( $r$ count $)$ of 0.700 with $p$-value 0.000 , soit can be concluded that there is a relationship or correlation between the quality of sleep with fasting blood sugar levels in young adults. If the sleep quality score gets lower then blood sugar levels will be lower, and vice versa. Suggestion: to do counseling efforts to improve poor sleep quality to anticipate the risk of diabetes.
\end{abstract}

Keywords: Sleep quality, fasting blood sugar level, diabetes mellitus, young adults

Abstrak: Individu dituntut untuk memenuhi kebutuhan dasar manusia, salah satunya adalah tidur. Gangguan tidur memainkan peran penting dalam terjadinya perkembangan diabetes melalui jalur metabolisme neuro endokrin. Orang yang menderita gangguan tidur, kualitas tidur atau kuantitas tidur mengalami penurunan sensitivitas insulin dan akibatnya terjadi peningkatan glukosa darah. Tujuan dari penelitian ini adalah untuk mengetahui hubungan antara kualitas tidur dengan kadar gula darah puasa pada usia dewasa muda. Desain penelitian menggunakan korelasional dengan pendekatan crosssectional. Teknik pengambilan sampel purposive sampling dan melibatkan 38 responden yang dipilih berdasarkan kriteria inklusi. Instrumen yang digunakan adalah kuesioner Pittsburgh Sleep Quality Index (PSQI) dan blood glucose meter. Teknik statistik yang digunakan adalah uji Pearson. Hasil penelitian ini menunjukkan bahwa dari 38 responden hampir seluruh responden memiliki kualitas tidur buruk sebanyak 31 responden $(81.6 \%)$ dan sebagian besar responden masuk dalam kategori prediabetes sebanyak 20 responden (52.6\%). Dari hasil uji korelasi Pearson didapatkan ( $r$ hitung) sebesar 0.700 dengan $p$-value 0.000 sehingga dapat disimpulkan bahwa terdapat korelasi antara kualitas tidur dengan kadar gula darah puasa pada usia dewasa muda. Apabila skor kualitas tidur semakin rendah maka kadar gula darah akan semakin rendah, demikian pula sebaliknya. Saran: perlu dilakukan upaya penyuluhan tentangmemperbaiki kualitas tidur yang buruk untuk mengantisipasi resiko diabetes.

Kata kunci: Kualitas Tidur, Kadar Gula Darah Puasa, Diabetes Melitus, Dewasa Muda

\section{PENDAHULUAN}

Diabetes mellitus adalah penyakit kronis yang disebabkan oleh kekurangan dalam produksi insulin oleh pankreas, atau oleh ketidakefektifan insulin yang dihasilkan (WHO, 2018). Data barudari International Diabetes Federation (IDF) Atlas tahun 2017 menunjukkan bahwa Indonesia menduduki peringkat ke-6 dunia dengan jumlah diabetes sebanyak 110,3 juta jiwa. Jika tidak ditangani dengan baik, WHO bahkan mengestimasi angka kejadian diabetes di Indonesia akan melonjak drastis menjadi
21,3 juta jiwa pada tahun 2030 (Simatupang, 2018).

Proporsi penderita diabetes melitus meningkat seiring dengan bertambahnya usia, prevalensi tertinggi pada kelompok usia 65 tahun keatas. Dari berbagai penelitian epidemiologis di Indonesia sekitar tahun 1980an prevalensi diabetes melitus pada penduduk usia 15 tahun ke atas sebesar $1,5-2,3 \%$, sedangkan proporsi dan perkiraan jumlah diabetes pada penduduk usia 15 tahun ke atas di Indonesia tahun 2013 sebesar 6,9\% (Kemenkes, 2014). Sedangkan menurut (PERKENI, 2015) 
prevalensi DM pada penduduk usia 15 tahun ke atas sebesar 10,9\%. Berdasarkan pola pertambahan penduduk, diperkirakan pada tahun 2030 nanti akan ada 194 juta penduduk yang berusia di atas 20 tahun dan dengan asumsi prevalensi DM pada urban $(14,7 \%)$ dan rural $(7,2 \%)$ maka diperkirakan terdapat 12 juta penyandang diabetes di daerah urban dan 8,1 juta di daerah rural (PERKENI, 2011).

Berbagai perubahan pola perilaku dan gaya hidup pada remaja dan dewasa muda dapat mempengaruhi kualitas tidur. Kebiasaan mengkonsumsi makanan yang tidak sehat, konsumsi alkohol, merokok, keluar hingga larut malam, menonton televisi berlebihan, kebiasaan bermain game di komputer atau laptop maupun playstation hingga bergadang, dan tentunya hal tersebut akan mempengaruhi kualitas tidur. Selain itu kondisi mental remaja dan dewasa muda yang masih labil sering memicu terjadinya stres yang juga dapat mempengaruhi kualitas tidur (Sastrawan dan Griadhi, 2017). Menurut data dari Sleep Heart Health Study, durasi tidur singkat yang disebabkan oleh pembatasan perilaku waktu tidur juga dapat menempatkan individu pada resiko diabetes (Zizi et al., 2010).

Beberapa penelitian dari Barone dan Barreto, Spiegel et al dan Cauter et altelah mengakui bahwa gangguan tidur sebagai faktor resiko baru untuk diabetes. Gangguan tidur memainkan peran penting dalam terjadinya perkembangan diabetes melalui jalur metabolisme neuro endokrin. Orang yang menderita gangguan tidur, kualitas tidur atau kuantitas tidur mengalami penurunan sensitivitas insulin dan akibatnya terjadi peningkatan glukosa darah sehingga memperparah kemajuan diabetes (Zhu et al., 2014).

Akibat berkurangnya waktu tidur dapat mempengaruhi fungsi sistem endokrin terutama terkait dengan gangguan toleransi glukosa, resistensi insulin dan berkurangnya respon insulin. Perubahan sistem endokrin yang terjadi selama periode tidur malam berhubungan dengan adanya sekresi beberapa hormon (Spiegel et al., 2015) .Menurut (Zuo et al., 2012) apabila aktifitas fisik total dan durasi tidur seseorang rendah maka peluang resistensi insulin akan meningkat.
Individu dituntut untuk memenuhi kebutuhan dasar manusia guna mempertahankan kelangsungan hidupnya. Salah satu kebutuhan dasar yang diperlukan manusia adalah tidur. Tidur merupakan kebutuhan dasar yang dibutuhkan oleh semua orang. (Safriyanda, Karim dan Dewi, 2015).

Menurut data diatas Diabetes Melitus masih menjadi masalah kesehatan masyarakat dan prevalensi penyakit ini juga masih terus meningkat. Peningkatan jumlah penderita juga diukuti dengan semakin mudanya umur penderita DM sehingga diperlukan usaha preventif dalam rangka mencegah terjadinya perburukan dengan melakukan metode-metode skrining.

Berdasarkanstudipendahuluan pada tanggal 4 Desember 2018 yang dilakukan di STIKes Maharanipada 20 orang mahasiswa usia sekitar 20-25 tahundengan cara tanya jawab. Dari hasiltersebutdidapatkan bahwa 15 orang mahasiswa memiliki kebiasaan tidur larut malam disebabkan karena mengerjakan tugas dan bermain gadget, 12 mahasiswa memiliki kebiasaan waktu tidur kurang dari 5 jam, 9 mahasiswa mengatakan sering terbangun saat tidur malam, 16 orang mahasiwa mengatakan tidak puas dengan tidurnya, 18 orang mahasiswa memiliki kebiasan makan makanan ringan serta makanan berat sebelum tidur, dan 5 orang mahasiswa mengatakan memiliki riwayat DM dalam keluarga. Dari studi pendahuluan tersebut dapat disimpulkan bahwa 16 dari 20 mahasiswa memiliki gangguan atau kualitas tidur yang buruk.

Berdasakan latar belakang tersebut dan tingginya jumlah penderita diabetes melitus dari tahun ke tahun, maka penulis tertarik untuk melakukan penelitian tentang pengukuran kadar gula darah puasa pada usia dewasa muda berdasarkan kualitas tidur.

\section{METODE PENELITIAN}

Penelitian ini merupakan penelitian kuantitatif dengan pendekatan crosssectional. Penelitian ini dilakukan di STIKes Maharani. Populasi pada penelitian ini adalah seluruh mahasiswa STIKes Maharani yang berjumlah 380 mahasiswa. Teknik sampling yang digunakan adalah 
purposive sampling dan melibatkan sampel sebanyak 38 responden yang memenuhi kriteria inklusi dan eksklusi penelitian.

Pengumpulan data dilakukan di STIKes Maharani pada tanggal 05-11 Mei 2019 dilakukan oleh peneliti dan 3 orang teman peneliti. Instrumen yang digunakan adalah Pittsburgh Sleep Quality Index (PSQI) dan bloodglucose meter. Sebelum pengambilan data responden diberikan penjelasan untuk puasa 8 jam sebelum kegiatan dimulai sesuai kontrak waktu yang telah disepakati.

\section{HASIL PENELITIAN}

1. Karakteristik responden berdasarkan data umum

\begin{tabular}{cccc}
\hline Ket & Kategori & $\mathbf{F}$ & $\%$ \\
\hline & 20 & 10 & 26.3 \\
& 21 & 8 & 21.1 \\
Usia & 22 & 13 & 34.2 \\
& 23 & 5 & 13.2 \\
& 24 & 1 & 2.6 \\
Total & 25 & 1 & 2.6 \\
Jenis Kelamin & $\mathbf{3 8}$ & $\mathbf{1 0 0}$ & \\
Total & Laki-laki & 5 & 13.2 \\
& Perempuan & 33 & 86.8 \\
IMT & $\mathbf{3 8}$ & $\mathbf{1 0 0}$ & 13.2 \\
& Underweight & 5 & 63.2 \\
Total & Normal & 24 & 5.3 \\
Keturunan DM & Overweight & 2 & 18.4 \\
Total & Obesitas I & 7 & 36.8 \\
\hline & $\mathbf{3 8}$ & $\mathbf{1 0 0}$ & 63.2 \\
\hline
\end{tabular}

Sumber : Data Primer 2019

Berdasarkan tabel di atas, dari 38 responden didapatkan hasil bahwa hampir setengahnya berusia 22 tahun yaitu sebanyak 13 orang (34.2\%). Hampir seluruh responden adalah perempuan yaitu sebanyak 33 orang (86.8\%). Dan sebagian besar IMT responden masuk dalam kategori normal sebanyak 24 responden (63.2\%). Sedangkan berdasarkan keturunan DM didapatkan hasil bahwa sebagian besar responden tidak memiliki keturunann DM dalam keluarga sebanyak 24 responden (63.2\%).

2. Karakteristik Responden Berdasarkan Kualitas Tidur

\begin{tabular}{ccc}
\hline Kualitas Tidur & $\mathbf{F}$ & $\%$ \\
\hline Baik & 7 & 18.4 \\
Buruk & 31 & 81.6 \\
Total & 38 & 100.0 \\
\hline
\end{tabular}

Sumber : Data Primer 2019

Berdasarkan tabel di atas, dari 38 responden didapatkan hasil bahwa hampir seluruh responden memiliki kualitas tidur buruk sebanyak 31 responden (81.6\%).

3. Karakteristik Responden Berdasarkan Kadar Gula Darah Puasa

\begin{tabular}{ccc}
\hline Kadar Gula Darah & F & $\%$ \\
\hline Normal & 18 & 47.4 \\
Prediabetes & 20 & 52.6 \\
Total & 38 & 100 \\
\hline
\end{tabular}


Berdasarkan tabel di atas, dari 38 responden didapatkan hasil bahwa sebagian besar kadar gula darah responden masuk dalam kategori prediabetes sebanyak 20 responden $(52.6 \%)$.

\section{Tabulasi Silang Kualitas Tidur dengan Kadar Gula Darah Puasa}

\begin{tabular}{ccccccc}
\hline Kualitas Tidur & \multicolumn{2}{c}{ Kadar Gula Darah } & \multicolumn{2}{c}{ Total } \\
& Normal & $\%$ & Pre & $\%$ & $\mathrm{~F}$ & $\%$ \\
\hline Baik & 7 & 15.8 & 0 & 0 & 7 & 18.4 \\
Buruk & 11 & 31.6 & 20 & 52.6 & 31 & 81.6 \\
Total & 18 & 47.4 & 20 & 52.6 & 38 & 100 \\
\hline
\end{tabular}

Sumber : Data Primer 2019

Berdasarkan data tabel 5.9 hasil uji tabulasi silang yang dilakukan didapatkan hasil bahwa sebagian besar responden sebanyak 20 responden (52.6\%) memiliki kualitas tidur buruk dengan kadar gula darah prediabetes.

\section{Hasil Uji Pearson}

\begin{tabular}{lcc}
\hline Uji Pearson & Kadar Gula Darah Puasa & \\
\hline Kualitas Tidur & $r$ & 0.700 \\
& $p$-value & 0.000 \\
& $n$ & 38 \\
\hline
\end{tabular}

Sumber : Data Primer 2019

Berdasarkan tabel 5.10 hasil uji korelasi Pearson didapatkan nilai koefisien korelasi Pearson sebesar $(r$ hitung $)$ sebesar 0.700 dengan $p$-value 0.000 . Nilai $p$-value $\alpha a(0.000<0.05)$, hal ini menunjukkan hasil yang signifikan antara kualitas tidur dengan kadar gula darah puasa. Dan diketahui nilai ( $r$ hitung) sebesar $0.700>$ nilai $(r$ tabel $)$ sebesar 0.320 , maka dapat disimpulkan bahwa ada hubungan atau korelasi antara kualitas tidur dengan kadar gula darah puasa pada usia dewasa muda. Koefisien korelasi Pearson dalam analisis ini bernilai positif dengan derajat hubungan kuat. Artinya, hubungan yang terjadi antara kualitas tidur dengan kadar gula darah bernilai positif atau searah. Apabila skor kualitas tidur semakin rendah maka kadar gula darah akan semakin rendah, demikian pula sebaliknya.

\section{PEMBAHASAN}

Tidur merupakan kebutuhan mutlak bagi manusia, karena tubuh manusia tidak terbuat dari mesin yang dapat bekerja terusmenerus. Menurut penelitian, masih banyak orang beranggapan bahwa tidur merupakan suatu fase istirahat pasif untuk menghentikan kegiatan tubuh dan otak. Tidak seperti keyakinan umum, tidur adalah proses aktif yang melibatkan interaksi kompleks dengan fungsi metabolisme dan aktivitas dalam otak yang tinggi (Stefanie, 2015).

Berdasarkan hasil analisis didapatkan hasil bahwa hampir seluruh responden memiliki kualitas tidur yang buruk dan sebagian besar responden masuk dalam kriteria prediabetes. Berdasarkan hasil uji korelasi Pearson didapatkan nilai koefisien korelasi Pearson sebesar ( $r$ hitung) sebesar 0.700 dengan $p$ value 0.000 . Nilai $p$-value $<\alpha(0.000<0.05)$ , hal ini menunjukkan hasil yang signifikan antara kualitas tidur dengan kadar gula darah puasa. Dan diketahui nilai ( $r$ hitung) sebesar $0.700>$ nilai $(r$ tabel $)$ sebesar 0.320, maka dapat disimpulkan bahwa ada hubungan atau korelasi antara kualitas tidur dengan kadar gula darah puasa pada usia dewasa muda. Koefisien korelasi Pearson dalam analisis ini bernilai positif dengan derajat hubungan kuat. Artinya, hubungan yang terjadi antara kualitas tidur dengan kadar gula darah bernilai positif atau searah. Apabila skor kualitas tidur semakin rendah maka kadar gula darah akan semakin rendah, demikian pula sebaliknya.

Menurut peneliti berdasarkan hasil penelitian dengan menggunakan kuesioner $P S Q I$ komponen 5 gangguan tidur adapun beberapa faktor yang menyebabkan 
kualitas tidur yang buruk mahasiswa di STIKes Maharani disebabkan karena aktifitas yang padat dikampus maupun diluar kampus, terbangun ditengah malam, merasa kedinginan, jumlah jam tidur yang sedikit, kebiasaan tidur larut malam, tugas kampus yang menumpuk, kebiasaan bermain gadget dimalam hari dan lingkungan kos yang tidak mendukung seperti kamar kos yang panas dan terlalu ramai. Hal tersebut sejalan dengan penelitian Manalu (2013) kualitas tidur yang buruk pada usia dewasa muda dapat disebabkan oleh aktifitas sosial, karena pada usia dewasamuda seseorang sedang berada dipuncak keaktifan dalam aktifitassosial. Selain faktor aktifitas sosial,faktor elektronik juga sangatmempengaruhi kualitas tidurseseorang, seperti akses internet,peralatan elektronik yang ada dikamar tidur seperti televisi, gadget,dan komputer (Syamsoedin, 2015).

Menurut (Lou et al., 2014) kualitas tidur yang buruk dan durasi tidur yang pendek dapat merusak regulasi glukosa pada orang dewasa muda. Kadar leptin akan menurun dan sensitivitas insulin berkurang, penurunan sensitivitas insulin tersebut tidak dikompensasi oleh peningkatan pelepasan insulin akibatnya hal tersebut meningkatkan resiko diabetes dan toleransi glukosa terganggu. Jacobus (2016) menyatakan secara fisiologis saat tidur terjadi restorasi fungsi-fungsi tubuh manusia, tidak terkecuali homeostasis glukosa. Gangguan kuantitas dan kualitas tidur akan memicu gangguan toleransi glukosa dan menurunkan sensitivitas insulin yang pada akhirnya akan mencetuskan kejadian diabetes.

Dari hasil penelitian didapatkan hasil bahwa sebagian besar responden (52.6\%) memiliki kadar gula darah puasa prediabetes. Riwayat dalam keluarga serta faktor keturunan dapat menjadi penyebab yang penting terhadap kejadian penyakit DM karena pola familial yang kuat mengakibatkan terjadinya kerusakan sel-sel beta pankreas yang memproduksi insulin, sehingga terjadi kelainan dalam sekresi insulin maupun kerja insulin (Suriani, 2012). DM cenderung diturunkan atau diwariskan. Faktor genetik memberi peluang besar bagi timbulnya penyakit DM. Anggota keluarga penderita DM kemungkinan lebih besar menderita DM dibandingkan dengan anggota keluarga yang tidak menderita DM.

Namun berdasarkan hasil penelitian menunjukkan bahwa dari 20 responden $(52.62 \%)$ yang memiliki kadar gula darah prediabetes 10 responden (26.31\%) memiliki keturunan DM dalam keluarga dan 10 responden (26.31\%) tidak memiliki keturunan DM dalam keluarga. Hal tersebut menunjukkan bahwa tidak semua orang yang memiliki riwayat DM dalam keluarga akan memiliki potensi atau resiko menderita DM.

Obesitas juga menjadi salah satu faktor penyebab diabetes. Glukosa mensintesis asam lemak yang merupakan kandungan dari lemak tubuh.. Insulin menjadi hormon anabolik yang menghasilkan konservasi energi dan menandakan bahwa tubuh memproduksi lemak. Ketika BMI meningkat, resistensi insulin juga meningkat. Ketika terjadi resistensi insulin glukosa tidak dapat memasuki sel sehingga kadar glukosa cenderung meningkat (Agrawel et al.,2017). Keadaan ini lama-kelamaan akan menyebabkan pankreas kelelahan sehingga tidak mampu mengeluarkan insulin sesuai kebutuhan. Kondisi yang demikian menyebabkan glukosa yang dihasilkan berlebih dan tidak terkendali sehingga kadar gula didalam darah meningkat dan memicu resiko terjadinya diabetes (Zhong et al.,2011).

Pada penelitian ini didapatkan hasil 24 responden (63.15\%) memiliki IMT normal dengan 11 responden (28.94\%) memiliki kadar gula darah puasa kategori normal dan 13 responden (34.21\%) memiliki kadar gula darah puasa dalam kategori prediabetes. Selain itu juga didapatkan hasil dari 7 responden (18.41\%) dengan IMT Obesitas I 5 responden (13.15\%) diantaranya memiliki kadar gula darah kategori prediabetes. Dari hasil tersebut menunjukkan bahwa responden yang memiliki IMT normal lebih banyak yang masuk dalam kategori prediabetes. Menurut hasil tersebut dapat disimpulkan bahwa obesitas bukan satu-satunya faktor yang dapat mencetuskan kejadian diabetes pada penelitian ini. 


\section{KESIMPULAN DAN SARAN}

Hampir seluruh responden $(81.6 \%)$ memiliki kualitas tidur buruk dan sebagian besar (52.6\%) responden memiliki kadar gula darah puasa prediabetes. Terdapat hubungan yang positif dan signifikan antara kualitas tidur dengan kadar gula darah puasa pada usia dewasa muda. Koefisien korelasi Pearson sebesar 0.700 dan bertanda positif. Artinya apabila skor kualitas tidur semakin rendah maka kadar gula darah puasa juga semakin rendah dan

\section{DAFTAR PUSTAKA}

Agrawal, $\mathrm{N}$ et al. 2017. Correlation Between Body Mass Index and Blood Glucose Levels in Jharkhand Population. International Journal of Contemporary Medical Research. Vol. 4 Issue 8

Jacobus, D. J. (2016) 'Gangguan Tidur Meningkatkan Risiko Diabetes Melitus', 43(2), pp. 144-146.

Kemenkes, RI. (2014) 'Pusat Data dan Informasi Kementerian Kesehatan RI.pdf', p. 8.

Lou, P. et al. (2014) 'Interaction of Sleep Quality and Sleep Duration on Impaired Fasting glucose: a population-based cross-sectional survey in China', BMJ Open, pp. 17. doi: 10.1136/bmjopen-2013004436.

Manalu, A. N. (2013) 'Hubungan kualitas tidur dengan tekanan darah mahasiswa kedokteran angkatan 2012', Scholarly articles.

PERKENI (2011) Konsensus Pengelolaan dan Pencegahan Diabetes Melitus Tipe 2 di Indonesia 2011.

PERKENI (2015) Pengelolaan dan Pencegahan Diabetes Melitus Tipe 2 di Indonesia 2015.

Safriyanda, J., Karim, D. and Dewi, ari pristiana (2015) 'Hubungan antara Kualitas Tidur dan Kuantitas Tidur dengan Prestasi Belajar Mahasiswa', JOM, 2(2).

Simatupang, G. (2018) 'Total Kasus Diabetes di Indonesia Merupakan Diabetes Tipe 2'. sebaliknya apabila skor kualitas tidur semakin tinggi kadar gula darah puasa juga semakin tinggi.

Pengukuran kadar gula darah hendaknya menggunakan metode yang lebih akurat yaitu pemeriksaan kadar gula darah dengan cara enzimatik dengan bahan darah plasma serta meneliti faktor-faktor lain yang dapat mempengaruhi kadar gula darah yang tidak diteliti yaitu stres, penggunaan obat, siklus menstruasi, aktifitas fisik dan merokok.

Spiegel, K. et al. (2015) 'Effects of Poor and Short Sleep on Glucose Metabolism and Obesity Risk', 5(5), pp. 253$261 . \quad$ doi: 10.1038/nrendo.2009.23. Effects.

Stefanie, A. (2015) 'Perancanagan Komunikasi Visual Publikasi Buku “ Tidur : Langkah Cerdas Hidup Sehat "'

Suriani.2012. Gangguan metabolisme karbohidrat pada diabetes melitus, Program Pascasarjana IImu Biomedik. Fakultas Kedokteran Universitas Brawijaya, Malang.

Syamsoedin, W.(2015) 'Hubungan durasi penggunaan media sosial dengan kejadian insomnia pada remaja di SMA Negeri 9 Manado', Scholarly articles, pp. 6-8.

Viskayanesya (2012) 'Pemahaman Khalayak Dewasa Awal Mengenai Informasi Kesehatan di Media Konvesional dan Media baru'.

WHO (2018). https://www.ninds.nih.gov/ Disorders/Patient-CaregiverEducation/Understanding-Sleep.

WHO (2018) 'World Diabetes Day 2017: Women and Diabetes'.

Zhong, J. Z., Zhe, D., and Cheng, X. Y. A New Tumor Necrosis Factor (TNF)-A Regulator, LipopolysaccharidesInduced TNF- $\alpha$ Factor, is Associated with Obesity and Insulin Resistance. Chinese Medical Journal. 2011; 124(2): 177-182. 
Zhu, B. et al. (2014) 'Science Direct Sleep Quality and Its Impact on Glycaemic Control in Patients With Type 2 Diabetes Mellitus', International Journal of Nursing Sciences. Elsevier Ltd, 1(3), pp. 260-265. doi: 10.1016/j.jnss.2014.05.020.

Zizi, F. et al. (2010) 'Sleep Duration and The Risk of Diabetes Mellitus: epidemiologic Evidence and Pathophysiologic Insights', 10(1), pp. 43-47. doi: 10.1007/s11892-0090082-x.Sleep.
Zuo, H. et al. (2012) 'Interaction Between Physical Activity and Sleep Duration in Relation to Insulin Resistence Among Non Diabetic Chinese Adults', p. 9. 